\title{
Os estudos de antropologia da saúde/doença no Brasil na década de 1990
}

\author{
Health and illness' antrophological studies \\ in the 90's in Brazil
}

Abstract This article reviews and comments the anthropological and qualitative studies about the sociocultural dimensions of health and illness. It focus the different intellectuals positions, the concepts and methodologies and includes the theme sexuality, disease and genders relations. The article discuss some factors and its contributions to the academic production expansion, and is concerned only to the publications which its examination showed the main themes for selection.

Key words Anthropology of health/disease; Qualitative research in health; Concepts, methodologies and themes.
Resumo Este texto revê e comenta os estudos antropológicos e qualitati vos sobre as dimensões socioculturais da saúde/doença, englobando os seus subtemas, conceitos e metodologias adotadas a partir de diferentes vocações intelectuais. Inclui ainda a sexualidade, doença erelações de gênero. Traça al guns fatores que contribuíram para a expansão daquela produção acadêmica e circunscreve-se somente à publicada, cujo exame permitiu a seleção dos temas abordados, devido aos seus predomínios. Palavras-chave Antropologia da saúde/doença; Pesquisa qualitativa em saúde; Conceitos e metodologias e assuntos 


\section{Introdução}

Este texto revê o que fizeram no Brasil, na última década do século 20, os antropólogos e profissionais de saúde que incorporaram os referenciais teórico-metodológicos da antropologia nas suas pesquisas e reflexões, enquadradas numa especialização em constituição designada de antropologia da Saúde/D oença, que vem alcançando visibilidade e maior legitimidade acadêmica.

Na década de 1980 essa produção acadêmica foi objeto de análise, quanto a um conjunto de temas, perspectivas conceituais e metodológicas adotadas pel os pesquisadores; origens e influências recebidas (Canesqui, 1994). Outras recentes revisões e reflexões sobre as ciências sociais no campo da saúde ou específicas de alguns temas foram feitas (Canesqui, 1998; N unes, 2000; Alves, 1998), sendo agora pertinente nova análise dos estudos, na década de 1990, devido a sua forte expansão e amadurecimento.

A preocupação com o que somos, nossostemas e origens, quantos somos, para onde vamos foi uma das marcas das ciências sociais no campo da saúde durante a década de 1990, cujos registros estão na bibliografia enos eventos, patrocinados pela Associação de Pós-Graduação em Saúde Coletiva, que revelam a estreita interlocução daquelas ciências (sociologia, antropologia e ciência política) com o campo da saúde coletiva/saúde pública. Essa busca de identidade deu-se ainda na trajetória da antropologia, marcada pela "volta sobre si mesma" (Rubim, 1999).

A pesar da insistente busca da interdisciplinaridade, entre as próprias ciências sociais e destas com a Saúde Coletiva, a antropologia médica ou antropologia da saúde buscam identidades segundo as preferências e vocações de alguns proponentes, sejam dos mais preocupados em estabelecer fronteiras e limites mais nítidos e precisos para estes empreendimentos disciplinares, ou que reorganizam uma rede de estudiosos no assunto, sejam dos que preservam os espaços disciplinares mais pragmáticos, mediante forte interlocução interdisciplinar com a epidemiologia, o planejamento de serviços de saúde e psiquiatria (U choa et al., 1994; M inayo, 1998; Alves, 1998; Sevalho et al., 1998).

A estratégia mais "antropológica" e "holista" associou-se à contínua convocação, na década de 1990, de grupos de trabalho sobre pessoa, corpo e doença, pela Associação Brasilei- ra de Antropologia (ABA) e Associação Brasileira de Pós-Graduação em Ciências Sociais (ANPOCS). Ela quer estudar a construção das pessoas, do corpo ou das emoções, associados aos fenômenos da "doença" ou perturbações (D uarte, 1998), sem ser compartilhada igualmente por todos os pesquisadores, tal como se evidenciará na bibliografia disponível.

A busca de identidade de uma antropologia especializada na saúde e doença gera tensões entre as distintas vocações intelectuais e disputas entre os agentes, segundo as suas preferências intelectuais, fazendo ou não seus aliados, sendo que al gumas posturas, sob diferentes argumentos, são mais cautelosas quanto à partilha ou especialização dos objetos disciplinares (Duarte, 1994; Carrara, 1994), enquanto outros preferem a singularidade e identidade da nova especialidade.

0 fato éque esse embate intelectual não dispensa alianças e não foi casual a observação de Russo (1998) sobre o meio parentesco de afinidade entre a saúde coletiva e a "antropologia da saúde". É salutar a convivência de vários tipos de pesquisa - a básica, estratégica e operacional -, sugeridos por M inayo (1998), à medida que os dois primeiros podem atender às demandas setoriais da saúde, sem ser desprezada a enorme relevância da pesquisa básica na antropologia social. Confirma-se a importância da interdisciplinaridade na saúde coletiva/saúde pública, bem ao contrário das posturas críticas e mais reflexivas, que predominaram as contribuições das ciências sociais, nos estudos na década de 1970.

U m conjunto crescente de agentes responsabilizou-se pelo volume significativo de publicações no assunto pesquisado (livros, coletâneas e artigos de revistas de saúde pública/saúde coletiva e de antropologia social), que motivaram este tipo de revisão, a qual padece de parcialidade. U ma parte dos agentes está nos ambientes "híbridos" em interlocução com as ciências biomédicas, saúde pública, psiquiatria, gineco-obstetrícia e pediatria.

A outra se liga às áreas básicas das ciências sociais dos institutos de filosofia e ciências humanas e às linhas de pesquisas em antropologia, sociologia ou nas ciências sociais e saúde, através de alguns cursos de pós-graduação dos departamentos universitários, ou de centros e núcleos de pesquisas ( $N$ úcleo de Antropologia do Corpo, Saúde e D oença da U niversidade Federal do Rio Grande do Sul ou Núcleo de Ciências Estudos de Sociais e Saúde da U niversidade 
Federal da Bahia), ao lado de outros multidisciplinares mais antigos e não só circunscritos às pesquisas no assunto. Agentes ainda estão nas fundações e organizações não governamentais.

Outros fatores concorreram positivamente para a expansão da produção bibliográfica a ser anal isada, tais como: 1) a maior flexibilidade, na saúde coletiva e nas ciências sociais, para abrir-se a novos objetos que suscitam mudanças ou permanências nas visões de mundo e valores de nossa sociedade (a exemplo do gênero e sexualidade, a extensão dos direitos de cidadania); a emergência da Aids; os processos de desinstitucionalização da loucura, junto com a atuação de alguns movimentos sociais; 2 ) a re corrente ênfase nos processos não biológicos das enfermidades; 3) os novos critérios de avaliação dos cursos de pós-graduação que estimularam o mercado editorial com novas revistas, ampliação de edições de livros e artigos no assunto, dando vazão à crescente produção acadêmica; 4) o apoio às pesquisas pelas agências nacionais e o estímulo ao financiamento de estudos antropológicos por algumas fundações internacionais na promoção de temas como: gênero, sexualidade; saúde e reprodução, envolvendo a academia e organizações não governamentais, sendo que os estudos sobre a Aids estimularam-se por financiamentos internacionais e vigência do Programa $\mathrm{N}$ acional de DST/Aids do M inistério da Saúde que incluiu muitas pesquisas. Outros temas se estimularam acadêmica e politicamente, devido ao longo processo de reorganização dos processos de de sinstitucionalização da loucura, como a saúde mental, cujas pesquisas, de interesse a este trabal ho, mobilizaram redes multicêntricas nacionais e internacionais.

No plano do conhecimento, a maior desconfiança das dicotomias conceituais (material/ imaterial; objetivo/subjetivo; coletivo/individual; estrutura/ação) abriu flancos, nas teorias e metodologias das ciências sociais em geral e nas instadas no campo da saúde, para posturas que buscam compreender os fenômenos na multiplicidade de seus domínios, ultrapassando aquelas oposições. Se por um lado a abordagem do sujeito ou da ação passaram a ser privilegiados, seja na construção da realidade, sempre em busca dos sentidos na intersubjetividade, seja para desprovêlo de sua automática submissão às estruturas, por outro buscaram-se mediações entre as estruturas e a ação, mediante abordagens que procuram um construtivismo menos radical.
Essas críticas favoreceram os microestudos, sempre caros às abordagens antropológicas. Trata-se da abordagem fenomenológica, da retomada de correntes etnometodológicas, do interacionismo simbólico, das orientações "qualitativas", que permeiam os estudos a ser comentados adiante. Certamente estenão é um fato localizado entre nós e as "novas sociologias" (não tão novas muitas das correntes), junto com a maior interlocução entre filosofia, sociologia, antropologia, história, psicologia, delinearam-se como tendência em alguns meios acadêmicos na França (Concurff, 1995) e no Brasil.

A pluralidade e heterogeneidade nas diversas orientações teóricas e metodológicas são visíveis e reportadas pelos organizadores e comentaristas das várias coletâneas produzidas no assunto. N ão se trata de uma única antropologia, mas de várias orientações teóricas, que ora bebem nas fontes de autores franceses, ora nos norte-americanos, ora nos autores nacionais, sinalizando, por um lado, as múltiplas possibilidades de apreensão dos objetos etnográficose, por outro, refletem bem as peculiaridades da antropologia feita entre nós. Apesar de ela preocupar-se com a sociedade nacional, não deixa de ser universal, como antropologia, na interlocução com seus ancestrais e diferentes vocações internacionais, sofrendo contudo transformações na "periferia" (Oliveira, 1994a).

A seguir destacamos sel etivamente os temas pesquisados.

\section{D iferentes perspectivas nas abordagens da saúde/doença}

Não é peculiar à década de 1990 a centralidade dos estudos etnográficos sobre as representações de saúde e doença em geral, ou do corpo, saúde e doença ou de doenças específicas (tuberculose, Aids e hanseníase), em busca dos significados detidos para os grupos pesquisadose que refletem ainda sobre os limites das intervenções médicas, sempre tidas em dissonância com o universo cultural das classes trabalhadoras urbanas, que se tornaram o fulcro das pesquisas realizadas. Dos estudos feitos, uma parcela aprofundou conceitos e metodologias, enquanto outros se valeram de procedimentos etnográficos ou apenas do emprego de técnicas qualitativas para estudar o tema. 


\section{Representações: conceitos e metodologia}

0 emprego da noção de representação fezse, às vezes, de maneira frouxa e apenas referida a certas "imagens" da realidade. Em outro extremo confundiu-se na pesquisa, com a transparência dos discursos dos agentes sociais, cujas condições de inserção social as determinava. N uma outra vertente, a busca de signos, dos seus múltiplos sentidos e das profundas estruturas fechou a análise dos discursos, sem esclarecer as condições e o contexto de sua produção. As reações contrárias resvalaram-se para a "devolução das falas aos oprimidos" (M agnani, 1986). 0 conceito de representação foi ainda utilizado em substituição ao de simbolismo, detentor de grande tradição de análise no campo da antropologia. Derivou-se ainda das interlocuções entre disciplinas como a psicologia social, antropologia e sociologia, na busca do sentido e como forma de conhecimento.

0 emprego dessa noção, entre nós, parece movido por interesses bem similares aos postos por Herzlich (1991): a crise profunda dos esquemas globais de explicações, fundados nas determinações socioeconômicas; o retorno do sujeito, de sua experiência, "sentido" ou "vivido"; a intensificação dos processos de participação social e a interrogação do pesquisador sobre a sua posição em relação ao objeto de pesquisa. 0 conceito de representações sociais tornou-se uma metanoção e, em certos campos, foi objeto de empreendimentos inter ou transdisciplinares.

A assimilação desse conceito foi um pouco tardia entre nós, uma vez que desde a década de 1960 M ocovici (na psicologia social) e depois $\mathrm{H}$ erzlich (na sociologia), ambos ligados à escola francesa, resgataram da teoria durkheimeana as representações coletivas, tidas como categoria de pensamento social coercitiva às consciências individuais. M oscovici moldou- 0 , sob a denominação de representações sociais, articulando o coletivo ao individual, enquanto $\mathrm{H}$ erzlich se declara seguidora de Durkheim e dos antropólogos ingleses que estudaram o simbolismo ( $M$ ary Douglas), tendo proporcionado maior calibragem entre 0 indivíduo e a sociedade, ambos impregnando as noções de saúde e doença nos distintos grupos sociais franceses, por ela estudados, na década de 1960.

$\mathrm{Na}$ antropologia, $\mathrm{M}$ arcel M auss deixou uma lição importante. Enfatizou o quanto a atividade do pensamento coletivo é mais simbólica do que a do pensamento individual e as condutas individuais não são simbólicas em si mesmas e ganham sentido em relação a uma dada sociedade. Admite que as representações coletivas podem adotar formas concretas ou abstratas. No estudo sobre a magia, uma das primeiras expressões das representações coletivas, chamava a atenção para a sua composição: os agentes, atos e representações. 0 mago é 0 indivíduo que conduz a magia, mesmo que não seja um profissional. As representações mágicas são as idéias e crenças que correspondem aos atos mágicos e os ritos mágicos são atos que definem os demais elementos da magia e distintos das demais práticas sociais, e as técnicas disponíveis podem ou não ser acompanhadas da magia ( M auss, 1971).

Com o autor aprendemos que as representações mágicas não se restringem ao pensamento ou às idéias exclusivamente. Elas se expressam nos atos mágicos e se geram nos vários campos da vida social, incluindo os sistemas filosóficos esotéricos. Para desvendar as primeiras categorias lógicas utilizadas pelo pensamento humano, tanto M auss quanto Durkheim voltaram-se para a análise da organização social das sociedades primitivas. Em momentos de sua obra M auss desvencilhou-se do positivismo durkeimiano e trouxe aportes importantes para a moderna antropologia.

Da observação dos vários estudos internacionais sobre as representações de saúde e doença, Adam \& Herzlich (2000) apontam que, na interpretação dos fenômenos orgânicos, as pessoas se apóiam em conceitos, símbolos e estruturas interiorizadas, conforme os grupos sociais a que pertencem. Certas doenças firmamse no imaginário coletivo, enquanto outras, os indivíduos, em função de suas experiências e contexto, podem elaborar ou reelaborar interpretações, apoiando-se em recursos coletivos.

Entre nós, M inayo percorreu criticamente as correntes do pensamento sociológico clássico, sem que o conceito de representações fora assimilado por todas elas, e foi posta por Durkheim e seus seguidores, sempre preocupados com as idéias que os "povos primitivos" detinham sobre si e sobre o mundo ao redor. A objetividade do tratamento dos fatos sociais e de sua coerção sobre os indivíduos (incluindo as representações coletivas) despertou críticas ao autor, por outras correntes de pensamento: pelo marxismo, por não ceder às contradições 
e lutas; e pela fenomenologia e correntes compreensivas, por descurar-se do sujeito ou da ação social (M inayo, 1992).

No marxismo as representações remetem à ideologia e a autora toma as vertentes que não a concebem como mero reflexo das estruturas. Junta a dimensão cultural e o historicismo, que oferece espaço à criatividade do sujeito, sem descurar-se dos elementos estruturais, engendradores da sociedade capitalista. D estaca a importância dos estudos e representações sociais para a análise do social e a ação pedagógicopolítica transformadora. Elas retratam a realidade, sem reduzir-se às concepções dos atores sociais.

Toma as representações sociais como senso comum, idéias, imagens, concepções e visões de mundo. A representação social de indivíduos e grupos, nas palavras da autora, está pensada em relação às bases materiais quea engendram: de um lado temos o homem que é produto de seu produto: as estruturas da sociedade criam o seu ponto de partida; de outro, temos que este homem constrói a história dentro das condições recebidas ultrapassando-as e inscreve sua significação sobre toda a parte, em todo o tempo ea ordem das coisas (M inayo, 1992).

Queiroz (2000) também refletiu criticamente sobre o conceito, a partir de diferentes perspectivas sociológicas e antropológicas, no estudo das doenças endêmicas. Juntando M oscovici com Schultz toma-o como um tipo de saber socialmente organizado, contido no senso comum e na dimensão cotidiana, que permite ao indivíduo uma visão de mundo e o orienta nos projetos de ação e nas estratégias que desenvolve em seu meio. Afirma que as representações sociais são, portanto, conceitos culturalmente carregados, que adquirem sentido e significado pleno no contexto sociocultural e situacional onde manifestam (Queiroz, 2000).

Minayo \& Sanchez (1993) propuseram a complementaridade dos métodos qualitativos e quantitativos na pesquisa. Os primeiros se interessam pelo "nível mais profundo" em constante interação com o ecológico. Este nível comporta significados, motivos, aspirações, crenças e valores, expressos na linguagem da vida cotidiana e, bem se aplicam aos estudos de pessoas afetadas por doenças e a grupos determinados, historicamente situados. Se um dado objeto de pesquisa reclamar, sugerem a combinação dos métodos, que impõem, no plano do conhecimento, a relação entre objetividade e subjetividade. Os estudos quantitativos podem gerar questões a serem aprofundadas qualitativamente e vice-versa. A discussão de técnicas qualitativas para as pesquisas em saúde foi feita por M inayo e por outros que se interessaram no seu emprego nos estudos sobre representações sociais de saúde e doença (Rigotto, 1998).

Argumentos favoráveis à complementaridade dos métodos fundam-se na necessária discussão de vários pontos de vista na pesquisa (Ramos, 1993). A cautelam-se os que admitem a impossibilidade de aplicá-la generalizadamente, deixando intocadas as questões epistêmicas da objetividade/subjetividade, nas tentativas interdisciplinares da epidemiologia com as ciências sociais (Reichenhein, 1993; Santos, 1993).

Para potencializar o registro, obtenção e análise de dados etnográficos são adequados os usos de tecnologias eletrônicas e softwares. $\mathrm{Na}$ sistematização dos dados obtidos, os descritores conceituais e discursivos dos softwares permitem observar as recorrências de categorias e conceitos nos depoimentos dos informantes (Fachel et al., 1995; Victora et al., 2000). 0 emprego da análise fatorial por correspondência, uma técnica estatística, permitiu às autoras identificarem várias correlações tais como: entre "visão de mundo" e decisões sobre recursos de saúde e estratégias reprodutivas; as relações entre gênero e recursos de cura; as causas atribuídas à doença, entre outras. $N$ ão se trata de substituir o trabalho etnográfico e nem de descartar o esforço da análise antropológica, mas de buscar novas formas de sistematizá-las.

Cardoso \& Gomes (2000) advertem sobre o risco da incorporação acrítica, pelos estudos sociais em saúde, do conceito de representações sociais. Afirmam que o seu emprego não pode ignorar o já estabelecido por vários autores ligados à psicologia social e à sociologia no campo da saúde. Ao reverem o conceito nas teorias, discutem os limites da perspectiva construtivista e a necessária articulação da pesquisa com a abordagem histórica, dado o enraizamento simultâneo das representações nas realidades social e histórica, conforme posto pertinentemente por H erzlich (1991).

Recomendam o uso de múltiplas fontes (documentária e orais) para classificar as diferentes maneiras pelas quais os autores captaram 0 sentido do ser doente ou saudável; para estabelecer os nexos entre os sentidos de maneira a chegar à historicidade dos modelos de saúde e doença, e para reconstituir, nas fontes, "a lógica" pela qual as representações foram produ- 
zi das e socializadas na longa duração, que permite a maior compreensão dos model os atuais.

Demonstrou Laplantine (1986), sob ângulo da abordagem estruturalista, a existência de diferentes lógicas que presidem os model os etiológicos e terapêuticos na sociedade contemporânea, irredutíveis a uma única lógica. 0 resgate da historicidade dos sentidos ou significados das doenças, no longo alcance, é bastante plausível de ser tentada, retirando dos estudos o seu caráter meramente sincrônico e 0 atrelamento exclusivo às perspectivas dos adoecidos, desde que são múltiplas as fontes produtoras de representações sobre saúde e doença na soci edade.

São lembradas, nesse sentido, as abordagens da história das doenças, aproximando-se ou não de correntes antropológicas. Não setrata de retomar a produção dos estudos históricos, que foge dos propósitos deste texto. Os estudos de Carrara $(1994 ; 1996)$ exemplificam como a sífilis (mal coletivo e ameaça) mobilizou vários discursos e práticas, cujo desenrolar foi acompanhado desde os finais do século 19 até os meados da década de 1940. Em torno dela os médicos especialistas sifilógrafos, diz o autor, souberam com maestria fazer com que, pela sífilis, passassem não apenas o destino dos doentes, mas o de uma série de entidades que transcendiam o indivíduo: a família.... mas também a sociedade, a raça, a nação, a humanidade, a espécie (Carrara, 1996).

Ele mostra a articulação dos discursos médicos com outras forças e campos sociais, que engendram resoluções para o problema venéreo e todos eles geram representações sobre a doença. A sugestão do autor de se fazer uma antropologia da ciência, pela via do desenvolvimento conceitual da sífilis ou de sua construção social, requer o recurso a inúmeras fontes disponíveis, tais como: manuais clínicos, relatórios de pesquisa laboratoriais, livros didáti$\cos$, dentre outros que podem oferecer fontes mais teóricas para o estudo dos aspectos nosológicos da doença e sua terapêutica.

$\mathrm{Na}$ abordagem histórica das representações sociais da doença, Sevalho (1993) percorre um conjunto de autores como Foucault, Tamayo, Le Goff, Capra, Rosen, Canguilhen e outros, mostrando as continuidades e descontinuidades, das distintas concepções de doença, desde a Antiguidade até o início do século 20. Concordando com as palavras de Le Goff, citadas pelo autor, a doença pertence não só à história superficial dos progressos ci entíficos etecnológicos, como também à história profunda dos sa- beres e práticas ligadas às estruturas sociais, às instituições, às representações, às mentalidades. A história cultural das doenças abre um leque muito fértil às pesquisas, que não se restringem aos saberes eruditos.

Rodrigues (1999) fornece um outro bom exemplo da história das sensibilidades que passa nas fronteiras disciplinares, incluindo a compreensão da sensorialidade dos processos corporais, dos modos de sentir, do uso dos sentidos que não se restringem ao orgânico e são históricos, sempre remetidos na trama das relações sociais que Ihes atribuem sentidos. Resgata as continuidades e rupturas dessa história na constituição da sociedade ocidental.

Alves \& Rabelo (1998) reconhecem a contribuição dos estudos de representações e práticas de saúde e doença para o entendimento de matrizes culturais dos grupos sociais, que permitem ultrapassar a objetividade dos estudos epidemiológicos e apontam as limitações de seu uso: 1) a determinação das representações sobre as práticas; 2 ) a ênfase nos modelos fechados de significação (corpo, saúde e doença); 3) a necessidade de deslocar a aten ção da doença como fato (como dado empírico ou signo) para a doença como experiência. Resgatam as perspectivas fenomenológica e pragmática, associadas à interpretação hermenêutica. Colocam em relação o pensamento e a ação, a consciência e o corpo, a cultura e individualidade, cuja retomada dos estudos, sob esta perspectiva, será feita adiante.

\section{Representações do corpo, saúde e doença}

Reportando-se a autores nacionais e internacionais ( M auss; Durkheim; Bourdieu; Herzlich; Boltanski; Auge; M ontero; Loyola; Duarte), várias etnografias (Knauth, 1992; 1992; Victora, 1995; Oliveira, 1998) abordaram as representações do corpo e doença ou do seu funcionamento e estrutura, a partir dos pressupostos: 1) cada sociedade ou grupo social dispõe de maneiras específicas de conceber e lidar com 0 corpo, sendo que o saber biomédico contribuiu, ao longo da história, na difusão de sua naturalização, tida como universal; 2) da doença, como fenômeno social, que é capaz de estabelecer uma relação entre as ordens biológica e social, atingindo concomitantemente 0 indivíduo, no que deve à biologia - o seu corpo - , a sociedade e as relações sociais; e 3) das muitas indagações e significados, suscitados pela 
doença na sociedade, superando os estreitos limites biológicos do corpo e as explicações biomédicas.

Os estudos confirmam os achados de muitos outros: a percepção da doença dando-se através de al guns sinais e sensações corporais, indicativos de que "algo" impede o funcionamento "normal" do corpo (dor, febre, não dormir, não comer, fraqueza) e pela incapacidade de real izar as atividades cotidianas e de trabalhar, em qualquer modalidade assalariada ou não, assim vista por homens e mulheres.

Essa forma de perceber a doença bem expressa a importância do uso social do corpo como meio de existência para aqueles que deledependem para sobreviver. Assim, o significado da doença remete à ordem social, porque sua presença tanto afeta a reprodução biológica do indivíduo, quanto a sua reprodução social, em termos de reprodução das condições de existência (Knauth, 1992).

Além desse significado, Minayo acrescenta o peso das contradições e conflitos sociais do sistema de dominação que, uma vez transposto e mediado pelas relações estabelecidas da medicina do trabalho com as classes trabalhadoras, situa a doença na incapacidade para trabaIhar produtivamente, reproduzindo, no plano das idéias, o âmago das relações de apropriação e expropriação dos corpos dos trabalhadores na sociedade capitalista. Para os seus informantes "saúde é "riqueza", "fortuna", "tesouro", em oposição à doença, como castigo, desgraça, infelicidade e miséria" (M inayo, 1992).

Prossegue a autora, e a despeito do contato dos trabal hadores com as idéias dominantes, eles criam códigos próprios, conforme o lugar ocupado na sociedade, traduzidos no modo de vida. As representações da saúde e doença fundam-se ainda nas raízes tradicionais (crenças e valores) relativos ao corpo, vida morte e nas experiências de vida (M inayo, 1992). Outros autores conferem maior autonomia à "cultura popular" nos seus modos de significação, pela via do conceito de matrizes culturais de significações, como mediações capazes de re-semantizar e reordenar os elementos culturais produzidos por outro grupo, de modo que as mensagens da mídia e o próprio discurso médico podem ser reinterpretados nos termos daquela cultura (Leal, 1994).

Não se trata apenas de uma leitura que polariza dominados e dominantes, creditando aos primeiros resistência, conformismo ou transformação criativa das idéias dominantes, mas de apontar o quanto as mensagens veiculadas se transformam, através de outro referencial, norteador das práticas cotidianas, envolvendo uma visão de mundo e o sistema de representações sociais a respeito do corpo. Trata-se ainda de admitir as matrizes de significações culturais, suas diferenças e convivências, diante da heterogeneidade e coexistência dos sistemas de significação, presentes na sociedade.

Ferreira (1995) aprofundou o significado do "estar doente". A percepção se dá através de conjunto de sensações desagradáveis e sintomas (cansaço, fraqueza, dor, mal-estar, falta de apetite, sono, febre), sendo o corpo (sígnico) veiculador de mensagens que, ao serem apropriadas pelo médico ou pelo indivíduo, conduzem ao significado da doença.

A seu ver, a doença é uma construção social, e a cultura, plena de significações, somente tem valor se compartilhada pelo grupo social. Os relatos sobre a dor sinalizam o sofrimento; a enfermidade e o estar doente. Diz a autora que a percepção e os relatos a respeito da dor são influenciados por muitos el ementos. São eles a vivência cultural do doente, o seu repertório lingüístico, o seu domínio ou não dos termos médicos, suas crenças e representações sobre o corpo e doença, as suas experiências individuais e geral, e suas experiências e sua memória específica quanto à sensação de dor (Ferreira, 1995).

Os estudos de Victora (1995) e Leal (1994) ilustram as idéias que mulheres de grupos "populares" têm do funcionamento de seu corpo, quanto à sobreposição do período fértil e menstrual. Explicam essa concepção a partir de uma lógica do movimento de abrir e fechar 0 corpo e das qualidades de cal or e umidade associadas ao sangue menstrual. Com isso o período fértil associa-se, na concepção das muIheres, ao período menstrual, com implicações nas práticas contraceptivas.

Homens e mulheres percebem diferentemente os seus corpos. As mulheres Ihes dedicam maiores cuidados; preocupam-se com a estética e com a apresentação pública do corpo. Os homens, observados por Jardim (1992) nas conversas com eles nos bares, julgam que o excessivo embelezamento corporal sinaliza comportamento efeminado e compartilham o gosto "descuidado" e as comidas gordurosas. $\mathrm{Ne}$ gociam, no cotidiano, a busca da igualdade do gosto masculino, o que torna o corpo não apenas objeto de pensamento, mas um operador prático. 
Ferreira (1998) estudou as práticas de cuidados corporais a partir da experiência social e descartou a existência de model os que as presidem, uma vez que se embebem na ação, aproximando-se das posturas fenomenológicas. Essas práticas envolvem: 0 uso do médico, dos medicamentos e de outros recursos de cura (simpatias e remédios caseiros), uma vez percebidos os sinais corporais, junto com os cuidados com a higiene principalmente, sem que a idéia de prevenção esteja presente, tal como definida pela medicina. A noção de tempo, entre as classes populares francesas, estudadas por Boltanski (1979) deve ser melhor explorada na compreensão da dissonância entre o elevado grau de previsibilidade que os comportamentos médicos preventivos suscitam e o baixo grau dessa previsibilidade, tão presentes nas práticas daquelas classes. Os estudos sobre a Aids, como veremos, reiteram a ausência daquela idéia.

\section{Representações sobre doenças específicas}

Pesquisas das representações sobre a hanseníase e seu tratamento partem da experiência da clientela com os serviços de saúde; focalizam as relações sociais dos adoecidos e os significados atribuídos à doença. Destacam alguns aspectos: 1) as mudanças promovidas nas instituições médico-sanitárias na institucionalização dos adoecidos, antes excluídos e agora integrados à sociedade; 2) as modificações tecnológicas e terapêuticas para o tratamento; 3) os seus efeitos na redução do processo de estigmatização, uma vez alterada a forma de classificação dos doentes pela medicina; 4) a insuficiência da presença de sinais na pele na indicação da doença, uma vez que não impedem o uso intenso corporal nas atividades cotidianas; 5) o recurso a múltiplos tratamentos, os médicos, religiosos, os dietéticos e naturais (Claro, 1995; Queiroz \& Puntel, 1997).

Apesar da incorporação, no discurso dos profissionais de saúde, da designação oficial da doença, os entrevistados usam ainda o termo "lepra", acompanhado do estigma social. A redução do estigma pelos empenhos da medicina parece parcial e os estudos deixam entrever a persistência da autodepreciação dos adoecidos e preocupações com a preservação de sua imagem social, cuja análise não se reduz aos elementos de ordem subjetiva, conforme sugere um dos estudos. As causas da doença in- cluem, segundo Claro, as relacionadas ao mundo natural (ambiente, clima, contato com animais e substâncias tóxicas, sujeira e coisas poluídas); as individuais, centradas nos comportamentos morais, na hereditariedade e velhice; as sobrenaturais (karma, predisposição, fatalidade) e as alimentares, em especial, a ingestão da carne de porco, relacionada à idéia de sujeira. 0 contágio não é mencionado como causa da doença e os seus riscos se potencializam, diante da "fraqueza" corporal (Queiroz \& Puntel, 1997).

As representações sobre a tuberculose centram-se no "destino" e na percepção do corpo fragilizado, cujas causas incluem o desgaste físico, provocado pela exposição prolongada ao frio e ao trabalho, o enfraquecimento físicomoral, os efeitos da contaminação ambiental e da hereditariedade (Gonçal ves, 1998). A suspensão dos tratamentos médicos ocorre quando cessam os sinais corporais associados à doença; restauram-se as "forças" do corpo, voltase ao trabal ho e são retomados os papéis e obrigações familiares como sinalizadores da saúde, embora possam não estar totalmente curados, segundo a concepção médica.

A questão do abandono do tratamento médico, pesquisado pela autora, mostra que o oficialmente utilizado não está adequado ao modo de vida da clientela dos serviços de saúde. 0 abandono pode ser temporário ou definitivo, entre os al coólatras, os portadores de Aids; de distúrbios psicológicos e indigentes. Além disso, os tratamentos instituídos pelo uso regular e intenso de medicamentos não devem ser descartados dos motivos do seu abandono, ainda que uma parcela da clientela a eles se submeta e aceite as prescrições e condutas médicas, valorizando o seu poder de cura.

Diferenças de gênero, na percepção de doenças ou de suas causas, fazem-se na hanseníase: as mulheres se preocupam mais com a aparência corporal e com as deformidades físicas que a doença pode acarretar. Devido às razões estéticas ocultam a doença e, ao se relacionarem com os serviços de saúde movem-se pelos padrões físicos e morais, com forte preconceito e insatisfação com a perda de seu status na família, embora tendam a aceitar mais facilmente os diagnósticos médicos e busquem na religião as soluções alternativas para se livrarem do "castigo", que julgam merecer. Os homens relutam em aceitar os diagnósticos e as conseqüências da doença sobre as suas atividades ligadas à sobrevivência. Quando reconhecida a 
doença, reestruturam as suas vidas e as relações afetivas e sociais (Oliveira, 1998).

Os homens se referem ao desconhecimento das causas da "hipertensão" e, quando interrogados, hesitam em respondê-las. As mulheres as associam ao "nervosismo", ao excesso de alimentação (gordurosa) e ao al coolismo. Ela é mais percebida através das sensações corporais, como "tonturas", "zoeira na cabeça", "cansaço", "dor de cabeça" (Carvalho et al., 1998). O bserva-se que popularmente o termo hipertensão não é utilizado, e sim "pressão alta".

Ao cessarem essas sensações pelo uso da medicação e não se sentindo mais doentes, os idosos adoecidos entrevistados neste estudo tendem a abandonar o uso de medicamentos, embora incorporem mais facilmente a caminhada e a dieta com menos sal e gordura. A primeira prescrição implica o uso corporal mais intenso que encontra maior ressonância nas classes trabalhadoras, enquanto o uso de dietas contraria-Ihes as práticas e representações alimentares, uma vez que sal e alimentos gordurosos são valorizados por outorgarem "força" ao corpo que trabal ha. É provável que os homens ativos profissional mente resistam mais àquelas prescrições al imentares do que os aposentados, que foram objetos desta pesquisa.

Explorando as narrativas de pessoas ligadas ao pentecostalismo eàs casas de culto afro-brasileiro, Rodrigues et al. (1998) observam que o discurso das concepções e representações das causas das doenças envolve a ligação entre a pessoa e a moléstia, esta última como experiência física e subjetiva, enquanto as causas das doenças são referidas às explicações que permitem responder por que a doença ou o sofrimento ocorreu num dado momento das trajetórias de vida dos informantes, tratando-se de concepção de causal idade não linear e distinta da racionalidade médica. Assim sendo, a causalidade para o sofrimento associa-se ao plano físico, a partir da descrição corporal; ao plano de qualidades atribuídas à pessoa e a um plano não material remetido às relações sociais, do trabalho e ao plano mágico-espiritual.

Cada um desses planos engloba as categorias "êmicas" dos discursos dos informantes, submetidas a um esforço do pesquisador de construir um modelo de explicação da causalidade, a partir da experiência da pessoa em sua relação com a doença. Trata-se, nesta abordagem, de fazer prevalecer um sistema mais amplo de significações, perpassando as experiências, as noções de pessoa, sofrimento e identi- dade. Se o sofrimento pode fragilizar e desintegrar a pessoa, é também ponto de partida para a construção ou reconstrução da identidade social. N este caso, a análise dos rituais de cura, nas casas de culto afro-brasileiro mostra a incorporação de distintos modelos de realização de pessoa que, para terem sucesso, afirmam os autores, requerem a socialização prévia do adoecido ou de sua família. Assim, a adesão dos envolvidos dá-se apenas quando a ação mágica ou força sobrenatural evocam-se como causas do sofrimento.

Vários estudos antropológicos, enquadrados no tema representações sobre a Aids, se aproximaram dos adoecidos, dos soropositivos, das clientelas de serviços de saúde; de segmentos populacionais diversificados ou das classes trabalhadoras urbanas.

A epidemiologia, desde a emergência da Aids, valeu-se do conceito de grupos de risco para classificar uma ampla variedade de pessoas potenciais ou efetivos portadores da doença e seus comportamentos e, certamente, a difusão deste conceito muito contribuiu para que a percepção dessa doença se associasse à crença da "doença gay", "dos desviantes sexuais" (Loyola, 1994).

O estudo de Paulilo (1999), através das narrativas dos adoecidos de homens que fazem sexo com homens, conclui que o sentido dado ao "risco" nunca coincide com as idéias de grupos ou comportamentos de risco, incluídos no discurso epidemiológico. A partir das experiências subjetivas, intersubjetivas, dos contextos socioculturais e individuais, apreendeu os seguintes significados dados ao risco pelos informantes: a sua negação; a hierarquização; a afirmação de outros valores (prazer, vínculos afetivos, trocas ligadas ao sexo e ao uso de drogas); a desconfiança das afirmações da ciência médica versus a confiança no parceiro/parceira e a idéia de invulnerabilidade pela paixão e amor. Este estudo, como muitos outros feitos entre segmentos populacionais "sadios" sobre várias dimensões que cercam as percepções da Aids e dos comportamentos, chama a atenção para os limites das estratégias, conceitos e modelos que ancoram as intervenções médico-sanitárias (Corrêa, 1994; Loyola, 1994).

Outras reflexões sobre as representações da Aids centram-se nos elementos que a configuram simbolicamente e não apenas como doença física, mas na sua articulação com a sociedade e a cultura. A Aids evoca, simbolicamente, a morte, o sexo, o contágio, a punição, a acusa- 
ção e o pânico e múltiplas relações sociais: a negação, a culpabilização, o estigma, o preconceito e a discriminação, encarnando a representação do mal e das maledicências sobre o mal, no imaginário ocidental (Birman, 1994).

Ela condensa um conjunto de metáforas e associa-se a outras doenças desaparecidas, Iongínquas, como a peste, ou as mais modernas, como o câncer. No espaço público tornou-se objeto de múltiplas elaborações discursivas que Ihes deram sentido (Herzlich, 1992). Lembra a autora que a Aids é também um discurso sobre o "outro", o estranho, o longínquo e um discurso imputado ao outro. À medida que ampliaram a sua incidência e disseminação, nos grupos sociais empobrecidos, a Aids banalizou-se; deixou de ser a doença do "outro" longínquo, mas do "outro próximo" e "conhe cido" (Knauth et al., 1998). Gerou ainda o estigma do "aidético", deixou marcas nos seus corpos, desconfiou dos portadores e excluiu-os do convívio social (Seffener, 1995).

Comparando a Aids com a sífilis, afirma Carrara (1994): como a Aids hoje, a sífilis envolveu representações sociais muito amplas, que incidem sobre os mesmos pontos: a sexualidade (em especial os comportamentos considerados excessivos, desviantes e promíscuos), o medo do contágio e da contaminação; a decadência ou a possibilidade de uma morte coletiva. M orte, sexo e medo são temas associados à Aids, na divulgação feita pela imprensa eliteratura médica, na emergência da doença. Sua associação à homossexualidade, contribuiu para a estigmatização das escolhas sexuais.

Algumas religiões produziram um discurso de condenação dos comportamentos transgressores, usando a doença como símbolo de castigo divino (Ribeiro, 1990; Fernandes, 1990). O ativismo em torno da Aids muito contribuiu para as mudanças de atitudes em relação aos adoecidos, através da solidariedade e apoio e não da sua condenação e exclusão pelo preconceito (Galvão, 1994).

\section{Experiências esignificados da enfermidade ou do sofrimento}

Vários autores estudaram as doenças "mentais" ou a categoria "nervoso" entre as classes trabalhadoras urbanas, localizadas em vários pontos do país. U m grupo de pesquisas reportase a autores, oriundos da antropologia médica norte-americana, da corrente fenomenológica (M erleau-Ponty, H urssel, Schutz), junto com fi- lósofos e lingüistas hermeneutas, interacionistas simbólicos e etnometodólogos. Focalizam a experiência da enfermidade "mental". Empregam narrativas, estudos de caso ou as histórias de vida de adoecidos e de seus familiares, que permitem ao pesquisador reconstituir as interpretações, ambigüidades eincertezas dos discursos e práticas diante da doença, as escolhas dos tratamentos e sua avaliação (Alves, 1993; 1994).

Esses estudos partem da enfermidade, isto é, de sua experiência submetida à interpretação do senso comum - uma forma de conhecimento eminentemente prático, sendo sempre experimentada, vivida, manipulada e negociada de diferentes maneiras, diferindo-se do saber médico, que concebe a doença como fenômeno patológico e biológico.

Ao rever a literatura socioantropológica norte-americana sobre a questão da enfermidade, Alves (1993) sugere que a compreensão da enfermidade prende-se à experiência, contrapondo-se aos estudos de representações e às perspectivas sistêmica, estrutural ou históricoestrutural de análise. Nas suas palavras: éa experiência do sentir-se mal que, por um lado, origina por si mesma as representações da doença e, por outro, põe em movimento a nossa capacidade de transformar esta experiência em conhecimento. É através das impressões sensíveis produzidas pelo mal-estar físico ou psíquico que os indivíduos se consideram doentes.

Portanto, a enfermidade pressupõe, em parte, um processo subjetivo que é apreendido a partir de um conjunto de sensações corporais, sendo o corpo a matéria do mundo sensível e do próprio conhecimento e, pela construção do(s) significado(s) para o(s) outro(s), orienta-se nas relações sociais no mundo da vida cotidiana, naquele sentido dado por Schutz ao senso comum. Este é capaz de fornecer códigos de referência para os indivíduos, da mesma forma que as suas biografias de vida estão eivadas de um conjunto de tipificações, que Ihes oferecem estoques de conhecimento à mão.

Sem que esta experiência prenda-se exclusivamente aos aspectos subjetivos, 0 autor afirma o seu caráter intersubjetivo, que fornece referências ou os padrões culturais, que são internalizados pelos indivíduos, ao mesmo tempo em que se formam os padrões nos processos e interpretações construídos na intersubjetividade. As análises produzidas, sob essa perspectiva, prendem-se aos microprocessos sociais, atendo-se à interpretação e remontagem 
dos discursos de seus entrevistados, na sua relação com o contexto em que foram produzidos, incluindo o sujeito, a fala, a resposta aos eventos, pessoas e outras falas (Rabelo, 1999).

Por esta via os autores identificam, interpretam e demonstram como indivíduos, oriundos das classes populares, lidam com a "doença mental", um problema que requer soluções e a mobilização de um conjunto de decisões e de recursos terapêuticos. As inúmeras publicações, feitas individualmente ou em colaboração por Alves e Rabelo e seus colaboradores, reuniram-se, em parte, nas coletâneas (Alves \& Rabelo 1998; Rabelo et al., 1999). A pesar de algumas diferenças nas suas abordagens reiterarem sempre que a experiência não decorre apenas de modelos internalizados, sendo o doente um personagem capaz de comunicar e refletir sobre ela.

Ao libertarem os sujeitos das amarras das determinações, estes ganham maior liberdade (às vezes excessiva), diante de quaisquer constrangimentos que possam pesar sobre eles. Há portanto, uma permanente e até excessiva fluidez dos processos socioculturais e a ausência de relações de força e poder, na "realidade" permanentemente construída e reconstruída.

As narrativas fornecem visibilidade às comunicações, hesitações, mudanças dos significados atribuídos nas interações sociais, antes muito esquecidas sob as macrodeterminações. Essas pesquisas contribuíram para evidenciar crenças e valores, construções de conhecimento e a construção dos significados dados pelos indivíduos à enfermidade. Deixam de abordar, quando analisam os itinerários terapêuticos, qualquer tipo de influência que possa ter a organização da produção/oferta de bens de serviços de cura (oficiais e não oficiais) nas escolhas terapêuticas e serviços, embora mostrem também em dadas experiências de cura os modelos religiosos de doenças (Rabelo, 1993).

Pela via das narrativas, Silveira (2000) desvendou o significado do "nervoso", analisando-o como experiência e linguagem sobre um conjunto de aflições e problemas sociais e individuais, e compreendeu as explicações sobre suas causas e os limites da biomedicina para lidar com este fenômeno. O utra pesquisa mostrou o seu caráter polissêmico, associado a vários signos: a violência e agressividade; a agitação e impaciência; a tristeza e isolamento, abarcando conjuntamente 0 "descontrole" e a "fraqueza dos nervos" (Rabelo, 1997). O "nervoso", como experiência fragilizadora, foi visto ainda a partir da interpretação e significação dadas por mulheres "nervosas" às múltiplas experiências socioafetivas e relacionais que afetam a construção de sua identidade ( $\mathrm{Hita}$, 1998).

As reflexões de Duarte, que pesquisou os significados do "nervoso" entre as classes trabalhadoras urbanas na década de 1980, continuam reiterando a centralidade da noção de pessoa que engloba aquele fenômeno na cultura ocidental moderna, comportando múltiplos sistemas simbólicos para explicá-la. São eles: a biomedicina; as teorias psicologizante e sociologizante, junto com as configurações culturais das classes populares brasileiras, latino-americana e presentes noutros grupos contemporâneos e oitocentistas (Duarte, 1994), que não individualizam ou psicologizam os "nervos", integrando-os na noção de pessoa (físico-moral).

Através de um culturalismo radical, 0 autor pretende criar uma teoria abrangente capaz de dar conta das continuidades e permanências das diferenças culturais, na cultura ocidental moderna, pela via comparativa. As categorias biomédicas, por esta e por outras abordagens etnográficas, ancoraram nos sistemas de significação.

As suas contribuiç̧ões recuperam a designação físico-moral para qualificar as concepções do "nervoso", entre as classes trabal hadoras, reconhecendo o caráter de vínculo ou mediação de que esses fenômenos se cercam nas relações entre a corporalidade em todas as demais dimensões da vida social, inclusive e eventualmente a espiritual ou transcendental (Duarte, 1998). Neste caso, o trabal ho etnográfico oferece material substantivo aos esforços comparativos, sendo-Ihes secundários os múltiplos arranjos ou variações que possam comportar as práticas sob outras configurações simbólicas no interior de situações ideológicas mais homogêneas e que podem, em dadas esferas (no consumo, por exemplo) e entre as novas gerações, vir a configurar mudanças ou a conquistar novos contornos, estranhos aos valores holistas prevalentes nas classes trabalhadoras, expostas ainda a futuras pesquisas.

Os estudos deste autor reafirmam o quanto a ideologia individualista não está presente na cultura da classe trabalhadora, e não é casual que recusem o psicologismo, embora não o façam em relação a todos os serviços e recursos diagnósticos e terapêuticos ofertados pela medicina, que são sistematicamente demandados 
e val orizados no universo das representações e no quadro das expectativas consolidadas de consumo por bens coletivos, dentre eles os de saúde, na sociedade urbano-industrial (Canesqui, 1992). É possível que a valorização da proteção social coletiva ancorada nos valores solidários coexista em segmentos da classe trabalhadora, com a ideologia da autoproteção social, que pela via liberalizante mais intensamente disseminada quer preencher aquelas expectativas.

A pesar do persistente antagonismo feito entre as racional idades "popular" e "médica", Duarte (1999) pertinentemente sugere que é preciso explorar com cuidado a crença nas representações populares na medicina e suas técnicas, especialmente nas que produzem a evidência empírica concreta do seu poder, tais como: as intervenções cirúrgicas, os aparelhos corretivos e as próprias cicatrizes, paralelamente ao fetichismo das radiografias, dos exames de sangue, das receitas e dos remédios.

Argumenta que não se pode negar a capacidade dos discursos dos profissionais de saúde e do médico de produzir sentido para as classes populares, apesar de sua reinterpretação. 0 discurso do médico, na sua prática profissional, vale-se da lógica do pensamento "concreto" e "selvagem", permitindo um mínimo de mediação entre os dois mundos simbólicos distintos. A necessária distinção entre as discussões paradigmáticas e a polarização dos saberes erudito e popular sugere $o$ deslocamento para a produção de sentido no âmbito da prática médica, em que também ocorrem formas de comunicação, ressocializações, aprendizagem, relações sociais, sem que tudo possa ser fruto exclusivo de relações de dominação e poder ou, sob outro ângulo, puras inadequações ou reações de resistência às intervenções.

\section{Gênero, sexualidade e doença}

Com o advento da Aids, nas pesquisas biomédicas foi ampliado o interesse em torno da distribuição e incidência da enfermidade; dos tipos de comportamentos transmissores do HIV/ Aids, da mesma forma que nas ciências humanas, nos movimentos sociais (feminista, gays e lésbicas) combinou-se a produção de conhecimento de natureza mais reflexiva com aquela capaz de informar, reduzir a discriminação social e de promover valores de dignidade, igualdade e equidade, ou o direito do cidadão às di- ferenças.

0 enfoque da(s) sexualidade(s) masculina prevaleceu na exígua liter atura antropológica nacional da década de 1980, que se expandiu na década de 1990, seja pelo advento da Aids ou pela interlocução multidisciplinar a respeito. Entre as disciplinas das ciências humanas, admite Loyola (1998), a antropologia está bastante apta para abordar a sexualidade, uma vez que, a partir das relações sociais, a diversidade social e cultural, os sistemas cognitivos e simbólicos são questões que se apresentam a partir deste objeto. Ao rever os estudos antropológicos clássicos e contemporâneos, conclui que a sexualidade foi abordada na sociedade e na cultura, dentro das normas que a regem e não foi segmentada como objeto em si.

Duas posições estão presentes em torno da sexualidade: 0 essencialismo e o construtivismo (Vance, 1995; H eilborn, 1999; Loyola, 1998). A primeira centra-se na natureza humana ( 0 instinto, a energia sexual), restringindo a sexualidade à fisiologia, reprodução da espécie e à pulsão psíquica. A segunda desconstrói, desnaturaliza e desuniversaliza as categorias e relações entre as categorias que marcam os estudos. $\mathrm{N}$ a versão radical do construtivismo, afirma Vance, prevalece a construção do desejo sexual pela cultura e pela história a partir das energias e capacidades do corpo. N outras vertentes os significados subjetivos, os comportamentos, a ideologia e o próprio corpo, suas funções e sensações, são incorporados e mediados pela cultura.

$\mathrm{N}$ a introdução da coletânea Sexualidades Brasileiras, Parker \& Barbosa (1996) defendem os necessários laços entre a ciência, ética e política para entender a sexualidade. Para vários autores, partícipes dessa coletânea, a sexualidade, as cren ças e conviçcões a respeito são modeladas pelos significados culturais e valores, pelo sistema de poder político e social e pel os processos históricos e rede de significados inseridos no mundo social. A sexualidade, como construção social, norteia os vários estudos e reflexões, opondo-se ao essencialismo, que, em função de uma razão universal, paira sobre as condutas e os significados do que seja sexual, restringindo-a às dimensões psíquicas e reprodutiva. Ao contrário, ela se impregna das convenções culturais que modelam a excitação, a satisfação erótica e as sen sações físicas, implicando processos de socialização (Parker, 1994).

Parker (1994) designa de "ideologia do ero- 
tismo" o sistema de representações culturais e constructos simbólicos que moldam uma leitura da compreensão erótica no contexto brasileiro, que se marca pela transgressão, como particularidade da cultura sexual no Brasil, onde "tudo pode acontecer" e a dicotomia ativo e passivo é estruturante das noções de feminilidade e masculinidade, servindo de princípio organizador de um mundo muito mais amplo de classificações sexuais da vida cotidiana brasileira. Sob o argumento de aquela ideologia não ser generalizante e nem compartilhada por todos, Guimarães (1996) e outros autores deslocam o seu ol har para as relações sociais concretas e vividas; as especificidades da sexualidade e sua ordenação por homens e mulheres das classes populares, movidas por outros códigos, em especial o do valor família, postos por Duarte (1986) e Sarti (1996) e a forte moralidade nas relações de gênero e sexualidade.

Gênero, sexualidade e Aids foi tema de várias pesquisas. D ois enfoques estão presentes nas análises sobre o gênero: 0 da construção social da identidade e a relacional (Leal \& Boff, 1996). A partir do segundo enfoque mostra a autora que: 1) a construção da identidade masculina requer a aprendizagem de códigos que a constroem como adulto e homem e que norteiam os papéis sexuais como ativos e passivos; 2) qualidades marcam a virilidade e feminilidade; 3) admite, em certos contextos, a dinâmica de gênero na concepção de sexualidade entre as classes populares através da justaposição de valores individualistas sobre os holistas, de maior individualização nas masculinidades e de menor, no universo feminino nas questões da intimidade e do desempenho sexual.

Evidências similares foram postas por $\mathrm{H}$ eilborn \& Gouveia (1999) na adoção de um discurso "moderno" (mais individualista) em torno da sexual idade e sexo, em setores daquelas classes, embora reiterem as formulações de Duarte (1986) e Sarti (1996), mostrando que as mulheres não expõem suas vidas privadas ao escrutínio público, quando se trata das relações sexuais e das possíveis doenças. Preservam e reproduzem a imagem ideal feminina de "muIher de verdade" que lhe confere dignidade moral (Guimarães, 1994).

As demais pesquisas sobre a maior vulnerabilidade das mulheres diante da contaminação pelo HIV/Aids, pelos próprios parceiros, evidenciam suas dificuldades de negociar a gestão dos riscos, pelo uso de preservativos (Barbosa, 1996), prevalecendo nesta negociação o mode- lo de comportamentos irregulares ou desviantes do modelo monogâmico, gerador de desconfiança do marido/companheiro ou da muIher/companheira (Guimarães, 1994). A noção de familiaridade do conhecimento do outro re ge a percepção das mulheres de proteção contra o HIV, embora não desconheçam as causas da doença (Guimarães, 1996).

As várias pesquisas de Knauth concluem sobre o silêncio generalizado das mulheres sobre a soropositividade e Aids; a sua recusa de se reconhecerem doentes ou contaminadas por seus parceiros e, nesta condição, não rompem a aliança com eles e nem os culpam e julgam ser da "natureza" do homem o experimento das drogas e da homossexualidade (na adolescência) e das relações sexuais com outras muIheres no espaço "da rua". Se doentes ou contaminadas, preservam ou resgatam o status de mãe ou esposa, ou de filha perante a família, desenvolvendo estratégias de enfretamento da doença, que reforçam a identidade de esposa/mãe (Knauth, 1997; 1999). Sugere a autora o reordenamento das relações de gênero diante da Aids e da doença em geral. Entre as mulheres e os homens a Aids sempre se apresenta como doença do "outro", conforme constaram os vários estudos.

\section{Conclusão}

Em síntese, pode-se dizer que os estudos examinados nos falam menos da doença em si e mais de sua articulação simbólica na construção das identidades sociais, relações de gênero e inserção nos parâmetros simbólicos estruturantes da cultura. Quando resgatam as práticas sociais são capazes de vislumbrar estratégias e maiores dissonâncias entre pensamento, normas e a ação social ou ainda, percorrendo as experiências e o senso prático exclusivamente, colocam em evidência os adoecidos, suas ações e a construção dos significados diante da doença e na busca da resolução de seus problemas de saúde, ocultando as regularidades sociais ou os padrões estruturantes, sejam os sociais e políticos, sejam os culturais e simbólicos.

Quando percorrem a história lançam luzes sobre a mutabilidade e historicidade dos significados ou representações da doença ou do corpo, mostrando, em certos casos, as fontes produtoras de sentido, dentre as quais está o saber médico entrelaçado com outros campos 
sociais e políticos, ultrapassando o restrito campo científico. Posta no âmbito da experiência aflitiva do indivíduo, na cultura e ideologia e no campo de lutas e contradições sociais, a doença e suas representações condensam múltiplas determinações. É na calibragem ou no percurso das mediações entre o coletivo/individual e estrutura/ação que se podem encontrar caminhos menos polarizados e construtivismos menos radicais.

Não se põe dúvida, após esta exposição, na densidade e importância dos estudos nos temas examinados. Devido a sua abrangência faltou espaço para abordar outros que foram pesquisados, destacando-se: a sexualidade e reprodução humana ou corpo e reprodução humana, que dispõem de uma revisão bastante atualizada, feita por Giffin \& Cavalcanti (2000), enfatizando a maneira como os homens se incluíram nestes estudos.

Não foram abordados os sistemas de cura, imersos nos campos religioso, nas demais medicinas, sob outras racionalidades, que se tornam cada vez mais incrementados na sociedade contemporânea, combinando-se com a medicina oficial e que são objetos de estudos sociológicos e antropológicos. Agregam-se a estes o uso de métodos qualitativos na avaliação dos serviços de saúde, juntamente com as análises das instituições, interven ções médicas, médico-

\section{Nota}

A revisão da literatura da produção acadêmica dos anos iniciais da década de 1990 foi feita graças ao apoio do $\mathrm{CN} \mathrm{Pq}$, através de bolsa de produtividade à pesquisa.

\section{Referências bibliográficas}

Adam P \& H erzlich C 2000. Sociologia da doença e da me dicina. Editora da U niversidade do Sagrado Coração, Bauru.

Alves PC \& Rabelo M CM (org.) 1998. Antropologia esaúde. Traçando identidade explorando fronteira. Fiocruz-Relume Dumará, Rio de Janeiro.

Alves PC \& Rabelo M CM 1998. 0 status das ciências sociais em saúde no Brasil: tendências, pp. 13-28. In PC Alves et al. (org.). Op. cit.

Alves PC \& Rabelo M CM 1998. Repensando os estudos sobre representações e práticas, pp. 107-121 In PC Alves \& M CM Rabelo (org.). Op. cit.

Alves PC 1993. A experiência da enfermidade: considerações teóricas. Cadernos de Saúde Pública 9(3) :263271.

Alves PC 1994. 0 discurso sobre a enfermidade mental, pp. 91-99. In PC Alves \& M CS M inayo (org.). Saúde sanitárias e psiquiatras. São emergentes temas como: envelhecimento e a juventude, vistas nas relações com a saúde, intervenções médicas e com o universo sociocultural que as constitui e modela; as tecnologias, relações sociais e significados, que tanto invadem o cotidiano, as aspirações, as que projetam imagens, modelam e recriam os corpos, imprimindo novas formas ao embel ezamento, maiores precisões dos diagnósticos e alterações na reprodução humana.

Faz sentido voltar os ol hos para outros segmentos sociais que não exclusivamente as classes trabalhadoras, predominantes nos estudos, como também estar atento para as transformações valorativas que possam estar operando no seu interior, em especial, na sua relação com a medicina, os médicos, instituições e profissionais de saúde e nas esferas do consumo e de outras relações sociais.

Não é mais invisível a antropologia da saúde/doença no Brasil, e os esforços nesta direção parecem bem-sucedidos, se forem permanentes, apesar das diferentes vocações intelectuais, cujo convívio mais indica a vitalidade da nova especialidade do que a sua inviabilidade, embora se espere, no âmbito da saúde coletiva, que as ciências sociais dialoguem entre si permanentemente e com as demais disciplinas, sem que se apartem nos limites estreitos das rígidas fronteiras especializadas. e doença: um olhar antropológico. Fiocruz, Rio de Janeiro.

Alves PC 1998. La antropologia médica en Brasil y el problema de la interdisciplinariedad en los estudios sobre salud, pp. 187-196. In R Briceño-Leon (coord.). Ciencias sociales y salud en America Latina: un balance. Fundación Polar, Caracas.

Barbosa RM 1996. A trajetória feminina da Aids, pp. 17 31. In R Parker \& J Galvão (org.). Quebrando o silêncio. Mulheres e Aids no Brasil. ABIA-IM S-UERJ-Re lume Dumará, Rio de Janeiro.

Birman J 1994. Sexualidade: entre o mal e as maledicências, pp. 109- 15. In M A Loyola (org.). Aids ea sexualidade. 0 ponto de vista das ciências humanas. Relume Dumará-U erj, Rio de Janeiro.

Boltanski L 1979. As classes sociais e o corpo. Graal, Rio de Janeiro. 
Canesqui AM 1992. Consumo e avaliação dos serviços de saúde, pp. 13-28. In AW Spínola (org.). Pesquisa social em saúde. Cortez Editora, São Paulo.

Canesqui AM 1994. N otas sobre a produção acadêmica de antropologia e saúde na década de 80, pp. 13-32. In PC Alves \& M CS M inayo (org.). Op. cit.

Canesqui AM 1998. Ciências sociais e saúde: três décadas de ensino e pesquisa no Brasil. Ciência \& Saúde Coletiva 3:131-168.

Cardoso M HCA \& Gomes R 2000. Representações sociais e história: referenciais teórico-metodológicos para o campo da saúde coletiva. Cadernos de Saúde Pública 16(2):449-606.

Carrara S 1994. Aids e doenças venéreas no Brasil, pp. 73-108. In M A Loyola (org.). Aids e a sexualidade: 0 ponto de vista das ciências humanas. Relume-Dumará, Rio de Janeiro.

Carrara S 1994. Entre cientistas e bruxos. Ensaios sobre dilemas e perspectivas na análise antropológica da doença, pp. 33-45. In PC Alves \& M inayo MCS (org.). Op. cit.

Carrara S 1996. A luta antivenérea no Brasil e seus modelos, pp. 17-37. In R Parker \& RM Barbosa (org.). Sexualidades brasileiras. Relume-Dumará, Rio de Janeiro.

Carrara S 1996. Tributo a Vênus. A luta contra a sífilis no Brasil, da passagem do século aos anos 40. Fiocruz, Rio de Janeiro.

Carvalho F et al. 1998. U ma investigação antropológica na terceira idade: concepções sobre a hipertensão arterial. Cadernos de Saúde Pública 14(3):617-621.

Claro LBL 1995. H anseníase. Representações sobre a doença. Fiocruz, Rio de Janeiro.

Concurff P 1995. As novas sociologias. Construções da realidade social. Editora da U niversidade do Sagrado Coração, Bauru.

Corrêa M 1994. M edicalização e a construção da sexualidade, pp. 17-140. In M A Loyola (org.). Op. cit.

Duarte LFD 1986. Da vida nervosa nas classes trabalhadoras urbanas. Jorge Zahar-CN Pq, Rio de Janeiro.

Duarte LFD 1994. A outra saúde mental, psicossocial, físico-moral, pp. 46-57. In PC Alves \& M CS M inayo (org.). Op. cit.

Duarte LFD 1998. Investigação antropológica sobre a doença, sofrimento e perturbação: uma introdução, pp. 9-27. In LFD Duarte \& OF Leal (org.). Doença, sofrimento e perturbação: perspectivas etnográficas. Fiocruz, Rio de Janeiro.

Duarte LFD 1998. Pessoa e dor no Ocidente. H orizontes Antropológicos 4(9):13-26.

Duarte LFD 1999. A medicina e o médico na boca do povo. Revista Antropológica 9:7-14.

Fachel JM G et al. 1995. O corpo como dado: material etnográfico e aplicação de análise fatorial de correspondência, pp. 37-55. In JMG Fachel \& OF Leal (org.). Corpo e significado. Ensaios de antropologia social. Editora da Universidade, Porto Alegre.

Fernandes M EL \& Arévalo El 1990. Aids e lideranças religiosas no Estado de São Paulo, pp. 80-92. In Ribeiro H (coord.). Aids: do preconceito à solidariedade: a partir da medicina, ciência do social e teologia. Paulinas, São Paulo.

Ferreira J 1995. Semiologia do corpo, pp. 363-390. In JM G Fachel \& OF Leal (org.). Op. cit.

FerreiraJ 1998. Cuidados do corpo em uma vila de classe popular, pp. 49-56. In LFD Duarte \& OF Leal (org.). Op. cit.
Galvão J 1994. Aids e o ativismo: o surgimento e a construção de novas formas de solidariedade, pp. 341350. In R Parker et al. (org.). A Aids no Brasil. ABIAIM S-Relume Dumará, Rio de Janeiro.

Giffin K \& Cavalcanti C 2000. Revista Estudos Feministas $7(1,2): 53-91$

Gonçalves HD 1998. Corpo doente: um estudo acerca da percepção corporal da tuberculose, pp. 105- $\mathbb{1 7}$. In LFD Duarte \& OF Leal (org.). Op. cit.

Guimarães CD 1996. "M as eu conheço ele": um método de prevenção do HIV/Aids, pp. 169-181.In R Parker \&J Galvão. Op.cit.

Guimarães CD 1994. M ulheres, homens e Aids: o visível e o invisível, pp. 217-230. In R Parker et al. (org.). A Aids no Brasil. ABIA-IM S-UERJ-Relume Dumará, Rio de Janeiro.

Guimarães CD 1996. M ais merece: 0 estigma da infecção sexual pelo HIV/Aids em mulheres. Estudos Feministas 2:295-318.

H eilborn ML \& Gouveia 1999. "M arido é tudo igual": mulheres populares e sexualidade no contexto da Aids, pp. 176-198. In RM Barbosa \& R Parker (org.). Sexualidades pelo avesso. Direitos, identidades e poder. IM S-U erj-Editora 34, Rio de Janeiro.

Heilborn M L 1999. Articulando gênero, sexo e sexualidade: diferença na saúde. II Congresso Brasileiro de Ciências Sociais e Saúde. A brasco-U nifesp. (M imeo).

Herzlich C \& Pierret J 1992. U ma doença no espaço público. A Aids em seis jornais franceses. Physis - Revista de Saúde Coletiva $\mathbb{1}(1): 7-35$.

Herzlich CA 1991. A problemática da representação social e sua utilidade no campo da doença. Physis - Re vista de Saúde Coletiva 1(20):23-34.

Hita M G 1998. Identidade feminina e nervoso: crises e trajetórias, pp. 179-213. In PC Alves \& M CM Rabelo (org.). Op. cit.

Jardim DF 1992. Corpo masculino: baixo corporal e masculinidade. Cadernos de Antropologia 5:24-41.

Jardim DF 1992. Espaço social e auto-segregação entre homens: gostos, sonoridade e masculinidade. Cadernos de Antropologia 5:29-39.

Knauth DR 1992. Corpo, saúde e doença. Cadernos de Antropologia 5:55-72.

Knauth DR 1992. Representações sobre doença e cura entre doentes internados em uma instituição hospitalar. Cadernos de Antropologia 5:24-39.

Knauth DR 1995. Um problema de família. A percepção da Aids entre mulheres soropositivas, pp. 379-390. In JM G Fachel \& OF Leal (org.). Op. cit.

Knauth DR 1997. "M aternidade sob o signo da Aids": um estudo sobre mulheres infectadas, pp. 18-27. In AO Costa (org.). Direitos tardios: saúde, sexualidade e reprodução na América Latina. Editora 34-Fundação Carlos Chagas, São Paulo.

Knauth DR 1999. Subjetividade feminina e soropositividade, pp. 121-136. In R Parker \& RM Barbosa (org.). Sexualidades pelo avesso: direitos, identidades e poder. IM S-U erj-Editora 34, Rio de Janeiro.

Knauth DR et al. 1998. A banalização da Aids. H orizontes Antropológicos (9):171-202.

Knauth DR 1998. M orte masculina: homens portadores do vírus da Aids sob a perspectiva feminina, pp. 183198. In LFD Duarte \& OF Leal (org.). Op. cit.

Laplantine F 1986. Antropologia da doença. M artins Fontes, São Paulo.

Leal OF 1994. Sangue, fertilidade e práticas contracepti- 
vas, pp. 127-137. In PC Alves \& M inayo M CS (org.). Op. cit.

Leal OF \& Boff AM 1996. Insultos, queixas, sedução e sexualidade: fragmentos de identidade masculina em uma perspectiva relacional, pp. 119-135. In R Parker \& RM Barbosa (org.). Op. cit.

Loyola M A 1994. Percepção e prevenção da Aids no Rio de Janeiro, pp: 19-72. In M A Loyola (org.). Aids e a sexualidade: o ponto de vista das ciências humanas. Relume-Dumará, Rio de Janeiro.

Loyola M A 1998. Introdução, pp. 7-15. In M A Loyola (org.). A sexualidade nas ciências humanas. Editora UERJ, Rio de Janeiro.

Loyola M A 1998. Sexo e sexualidade na antropologia, pp. 17-42. In M A Loyola (org.). Op. cit.

M agnani JGC 1986. Discursos e representação, ou de como os Baloma de Kiriwina podem encarnar-se nas atuais pesquisas, pp. 127-140. In RCL Cardoso (org.) A aventura antropológica: teoria e pesquisa. Paz eTerra, Rio de Janeiro.

M auss M 1971. Sociología y antropología. Editorial Tecnos $S / A, M$ adri.

M inayo M CS \& Sanchez 1993. O quantitativo-qualitativo: oposição ou complementariedade? Cadernos de Saúde Pública 9(3):239.

M inayo M CS 1998. A construção da identidade da antropologia na área da saúde, pp. 29-46. In PC Alves \& MCM Rabelo (org.). Op. cit.

M inayo M CS 1992. 0 desafio do conhecimento. Pesquisa qualitativa em saúde. Hucitec-Abrasco, São PauloRio de Janeiro.

M oscovici S 1994. Prefácio, pp. 7-16. In PA Guareschi \& S Jovchelovitch (org.). Textos em representações sociais. Vozes, Petrópolis.

Nunes ED 2000. A doença como processo social, pp. 217229. In AM Canesqui. Ciências sociais e saúde para o ensino médico. Hucitec-Fapesp, São Paulo.

Oliveira FJA 1998. Concepções de doença: o que os serviços de saúde têm a ver com isto?, pp. 81-94. In LFD Duarte \& OF Leal (org.). Op. cit.

Oliveira RC 1994a. 0 movimento dos conceitos em antropologia. Revista de Antropologia 36:13-31.

Parker R 1994. Corpos, prazeres e paixões: a cultura sexual no Brasil contemporâneo. Best Seller. São Paulo.

Parker R \& Barbosa R 1996. Sexualidades brasileiras. Relume-Dumará, Rio de Janeiro.

Parker R \& Galvão | 1996. Introdução, pp. 7-15. In R Parker \& J Galvão. Quebrando o silêncio. M ulheres e Aids no Brasil. Abia-IMS-UERJ-Relume-Dumará, Rio de Janeiro.

Paulilo M AS 1999. Aids: os sentidos do risco. Veras Editora, São Paulo.

Queiroz M S 2000. Representações sociais: uma perspectiva multidisciplinar em pesquisa qualitativa. In RB Barata \& R Briceño-León (org.). D oenças endêmicas: abordagens culturais e comportamento. Fiocruz, Rio de Janeiro.

Queiroz M S \& Puntel M A 1997. A endemia hansênica: uma perspectiva multidisciplinar. Fiocruz, Rio de Janeiro.

Rabelo M CM et al. (org.) 1999. Experiência de doença e narrativa. Fiocruz, Rio de Janeiro.

Rabelo M CM 1993. Religião e cura: algumas reflexões sobre a experiência religiosa das classes populares urbanas. Cadernos de Saúde Pública (3):316-325.

Rabelo M CM 1999. Narrando a doença mental no Nor- deste de Amaralina: relatos como realizações práticas, pp. 75-87. In M CM Rabelo et al. (org.). Op. cit.

Rabelo MCM \& Alves PC 1999. Significações e metáforas na experiência da enfermidade, pp. 171-185. In MCM Rabelo et al. (org.). Op. cit.

Rabelo M CM , Alves PC \& Souza IM A 1999. Signos, significados e práticas relativos à doença mental, pp. 43-73. In M CM Rabelo et al. (org.). Op. cit.

Ramos CL 1993. Debate do artigo de M inayo e Sanchez. Cadernos de Saúde Pública 9(3):257-258.

Reichenhein ME 1993. Debate sobre o artigo de M inayo e Sanchez. Cadernos de Saúde Pública 9(3):252-253.

Rigotto RM 1998. As técnicas de relatos orais e o estudo das representações sociais em saúde. Ciência \& Saúde Coletiva 3(1):16-129.

Rodrigues N \& Caroso CA 1998. I déia de sofrimento e representação cultural na construção da pessoa, pp. 137-147. In LFD Duarte \& OF Leal (org.). Op. cit.

Rodrigues JC 1999. O corpo na história. Fiocruz, Rio de Janeiro.

Rubim CR 1999. Um pedaço da nossa história. Historiografia da antropologia brasileira. BIB - Revista Brasileira de Informações Bibliográficas em Ciências Sociais 44:31-72.

Russo JA 1998. Resenha do livro de Luiz Fernando Dias Duarte e Ondina Fachel Leal (org.). Doença, sofrimento, perturbações; perspectivas etnográficas. H orizontes Antropológicos 9:331-316.

Santos RV 1993. Debate sobre o artigo de M inayo \& Sanchez. Cadernos de Saúde Pública 9(3):258-259.

Sarti C 1996. A família como espelho. U m estudo sobre a moral dos pobres. Editores Associados, Campinas.

Seffner F 1995. Aids, estigma e corpo, pp. 391-415. In JM G Fachel \& OF Leal (org.). Op. cit.

Sevalho G \& Castiel LD 1998. Epidemiologia e antropologia médica: a interdisciplinaridade possível, pp. 47-69. In PC Alves et al. (org.). Antropologia e saúde. Traçando identidade e explorando fronteira. Editora Fiocruz-Relume Dumará, Rio de Janeiro.

Sevalho G 1993. U ma abordagem histórica de representações sociais de saúde e doença. Cadernos de Saúde Pública 9(3):349-365.

Silveira M L 2000. 0 nervo cala, o nervo fala: a linguagem da doença. Fiocruz, Rio de Janeiro.

Souza IM A 1998. Um retrato de Rose: considerações sobre processos interpretativos e elaboração de histórias de vida, pp. 15-149. In LFD Duarte \& OF Leal (org.). Op. cit.

U choa E \& Vital JM 1994. A antropologia médica: elementos conceituais e metodologia para uma análise da saúde e doença. Cadernos de Saúde Pública 10: 493-504.

Vance C 1995. A antropologia redescobre a sexualidade: um comentário teórico. Physis - Revista de Saúde Coletiva 5(1):4-15.

Victora CG 1995. As imagens do corpo: representações do aparelho reprodutor feminino e reapropriação dos modelos médicos, pp. 77-83. In JM G Fachel \& OF Leal (org.). Op. cit.

Victora CG et al. 2000. Pesquisa qualitativa em saúde. U ma introdução ao tema. Tomo Editorial, Porto Alegre.

Artigo apresentado em 3/10/2002

Aprovado em 6/11/2002

Versão final apresentada em 12/11/2002 